\title{
Ethos institucional e phrónesis na construção de discursos
}

\author{
Elioenai dos Santos Piovezan
}

Roberta Maria de Souza Piovezan

\section{De artesãos e publicitários}

\footnotetext{
0 saber prático permite a um artesão construir com competência qualquer objeto que ele queira, como um banco de madeira, por exemplo. Esse saber vem da experiência adquirida ao longo de sua vida, com a observação do trabalho de outro artesão, a construção de uma teoria e a produção de seus próprios objetos. Para confeccionar o banco, ele precisará de ferramentas adequadas e um plano de ação. Com o devido tempo e condições de trabalho, nosso artesão deverá seguir procedimentos corretos e tomar as melhores decisões para atingir seu objetivo. Logo, a imaginação que revelou o desenho do banco e a ação que o concretizou resultarão no objeto novo, fruto de uma inteligência humana prática, de um saber empírico.

Esse saber prático, que Aristóteles (384-322 a.C.) chama de phrónesis, também pode contribuir para a construção do discurso retórico. Além de considerar a importância da virtude (areté) e da benevolência (eúnoia), relacionadas respectivamente ao ethos e ao pathos, o orador deverá focar a construção do seu discurso no logos, pois trata da razão ou do raciocínio
} 
lógico, em que precisa mobilizar seus conhecimentos prévios e considerar todas as variáveis presentes em um contexto retórico.

Imaginemos como orador um jovem publicitário. Ele precisará decidir, a partir de uma demanda, portanto uma necessidade, quais os procedimentos que melhor levarão à persuasão um determinado público-alvo. Para além das técnicas de redação publicitária, nosso jovem deverá utilizar de phrónesis, como saber prático, para construir um discurso completo, que considere fatores internos (características do produto associadas às necessidades reais ou potencialmente desejadas pelo interlocutor, histórico do produto e sua evolução de acordo com o perfil socioeconômico e cultural do público) e externos (conjuntura econômica favorável, histórico de recepção de produtos similares da própria empresa e dos concorrentes). Munido de todas as variáveis possíveis, o redator publicitário deverá elaborar seu discurso (verbal, verbovisual ou audiovisual) em que a sua experiência de vida o ajudará na constituição do ethos retórico, representando a imagem de uma empresa confiável, competente e responsável. Para isso, procurará evidenciar um ethos institucional fundamentado na phrónesis, com foco no modo lógico, ponderado, sensato, prudente, razoável e prático do discurso ou ato retórico.

A fim de compreender melhor as relações existentes entre as qualidades do orador, notadamente a phrónesis, e a construção do discurso, devemos revisitar o próprio conceito de phrónesis, apresentado por Aristóteles, Aubenque e Angioni; de logos, abordado por Ferreira e Mateus; de ethos institucional, explicado por Ferreira e Guimarães. Após essas breves reflexões, buscaremos identificar em dois textos antagônicos que circulam na mídia digital a forma como os oradores lidam com o saber prático na construção de seus atos retóricos. A questão polêmica é a implantação do programa Future-se, do Ministério da Educação, que interessa tanto aos gestores quanto aos professores e estudantes universitários, uma vez que afeta a vida administrativa e acadêmica das instituições de ensino em nível federal.

Por fim, é interessante observar que dois profissionais tão distintos no modo de produção e separados pelo tempo de existência de suas artes, o antigo artesão e o contemporâneo publicitário, partem de teorias que embasam o seu trabalho, mas que cotidianamente precisam mobilizar o saber prático para realizá-lo. Ambos movidos pela necessidade de conhecer o seu público e de persuadi-lo quanto à qualidade de seus produtos. 


\section{Phrónesis, logos e elocutio}

Em uma perspectiva filosófica, a phrónesis é compreendida por Aubenque $^{1}$ como "prudência", "virtude da boa deliberação" que, "após exame refletido das diferentes opções, se inclina, embora não necessite fazê-lo, e, nessa medida, se esforça por conduzir os homens e o mundo na direção do melhor 2". O autor, em sua obra "A prudência de Aristóteles", contribui para a redescoberta, em meados do século XX, dessa virtude e defende que "a phrónesis aristotélica é que melhor cumpria o programa de uma hermenêutica da existência humana voltada para a práxis".

Para Aubenque, a phrónesis aristotélica é usada para "designar o saber imutável do ser imutável, por oposição à opinião ou à sensação que mudam conforme seus objetos". Isso porque, segundo Aristóteles, na obra "De caelo" (Sobre o Céu), "sem a existência de naturezas imóveis não se pode ter conhecimento ou saber 5". De início, com Platão (428-348 a.C.), não havia uma distinção clara entre sophia e phrónesis, sendo que ambas podiam designar "a ciência do imutável" ou "o saber verdadeiro, filosófico". Mas é Aristóteles quem mais tarde designaria phrónesis como "virtude da parte calculativa ou opinativa da alma". Assim, temos sophia (sabedoria) que se refere ao necessário, "ignora o que nasce e perece", "imutável como o seu objeto", tratando-se de "uma forma de saber que ultrapassa a condição humana"; enquanto phrónesis (prudência, saber prático) refere-se ao contingente, "é variável segundo os indivíduos e as circunstâncias", possui um "caráter humano".

Entre as diferentes interpretações dadas ao termo no período pós-aristotélico, Aubenque destaca a do Padre Gauthier ${ }^{7}$ que, contrapondo uma visão anti-intelectualista, afirma que mesmo sendo a prudência um conhecimento de "tipo especial requerido por seu caráter prático, ainda assim é um conhecimento", uma vez que "na medida em que é 'prática', ou seja, imperativa, inclui o desejo e a virtude; mas enquanto 'intelectual', é determinação do fim e não somente dos meios: a escolha dos meios é apenas um dos momentos, o da eficácia, no interior de sua função total, indissoluvelmente teórica e prática ${ }^{8 "}$.

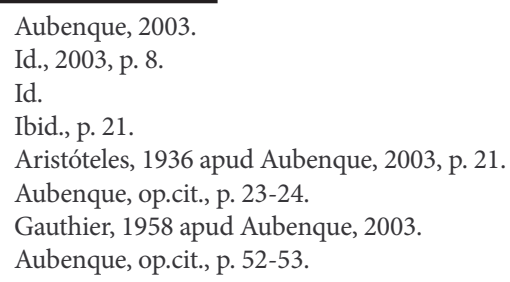


Outra abordagem, agora feita por Angioni, também considera a phrónesis "uma virtude intelectual que, acolhendo o fim correto adotado pela virtude do caráter, determina as condições efetivamente apropriadas para a realização desse fim (...), para além do propósito ou da intenção de agir bem "’. Notase que em seu estudo acerca do Livro VI da "Ética a Nicômaco", Aristóteles ressalta como traço relevante da phrónesis a consideração correta sobre as condições específicas de produção. Obviamente que não podemos esquecer "o caráter efetivo e eficaz da phrónesis", que, por sua vez, "não pode ser separado da compreensão dos fins moralmente bons ${ }^{10 "}$.

Em sua tradução e comentários, Angioni afirma que phrónesis, definida como "sensatez", envolve o fim correto adotado pelo caráter virtuoso e, portanto, não pode ocorrer separadamente da virtude do caráter. Por outro lado, sua tarefa propriamente intelectual (determinar a mediedade em atenção aos fatores singulares relevantes em cada ação) parece envolver duas camadas: "a boa deliberação, pela qual se formulam propósitos ainda gerais, e a percepção dos extremos, dos quais depende imediatamente a realização da ação moral ${ }^{11}$ ". Dessa forma, o saber prático, prudência ou sensatez chega à contemporaneidade como uma virtude, portanto associada à constituição do ethos do orador, que deverá fazer as melhores escolhas na elaboração de um discurso.

Outro aspecto observado em Aristóteles é o tratamento do "bem" como "alvo" (skopos) e este se atinge pela ação moral. Ora, partindo-se do pressuposto que um discurso visa ao bem, temos aí a busca de uma verdade. Esta se materializa no discurso ou ato retórico, que, na contemporaneidade, encontramos na forma de enunciados concretos, também consubstanciados em gêneros discursivos (ou, didaticamente, textuais) que apresentam relativa estabilidade notadamente em sua forma composicional, estilo de linguagem e conteúdo temático ${ }^{12}$. Mas esses enunciados concretos também resultam de uma relação dialética entre necessidade (ou desejo), criação de meios para satisfazê-la e sua execução, que no final das contas, representará uma verdade naquele momento.

Ainda na "Ética a Nicômaco", Angioni apresenta a prohairesis como "princípio motivador que leva a agir ${ }^{13}$ " e que "envolve apenas uma deter-

9 Angioni, 2011, p. 306

10 Ibid.

11 Aubenque, 2003, p. 306.

12 Bakhtin, 2011.

13 Angioni, 2011, p. 306. 
minação genérica sobre o que fazer em geral, a qual, para a realização de cada ação, será completada ou preenchida pelo cômputo correto dos fatores singulares envolvidos nas circunstâncias da ação - cômputo correto que é da alçada da phrónesis ${ }^{14 "}$. Mais uma vez tem-se a ideia de que phrónesis está na construção do discurso e o que se espera, ao fim e ao cabo, de um discurso eficaz é a razão correta ou orthos logos, ficando a construção e expressão, ou seja, a dispositio e a elocutio por conta da estruturação e rede de sentidos dali possíveis de serem criadas.

Segundo Aristóteles, o desejo por um fim representado pela prohairesis também envolve pensamento. Estaríamos assim, de um lado, diante de um "bem realizável pelo agente"; de outro, de um "raciocínio deliberativo" que, "assumindo como ponto de partida o fim eleito pelo desejo, calcula o modo pelo qual tal fim poderia vir a ser realizado ${ }^{15}$ ". Da mesma forma como é apontado por Bazerman ${ }^{16}$, para quem a necessidade de mudar a paisagem associa-se a kairós (momento oportuno), gerando um fato social pela ação letrada e que "esse desejo mais determinado é motivo que leva à ação ${ }^{17 "}$ ".

Na contrapartida à phrónesis, está a hybris, que, de acordo com Aubenque, é a "desmesura", que "quase se poderia traduzir por imprudência, atribuindo a esta palavra toda a sua força" e que "era para os gregos a falta por excelência, causa de todas as infelicidades privadas e públicas ${ }^{18 ” . ~ A l c ̧ a n d o ~ a ~ h y b r i s ~}$ ao posto da irresponsabilidade humana, o autor reconhece traços desse fenômeno em discursos e práticas atuais, como "a insistência ideológica, a obstinação axiológica, a arrogância tecnológica e mesmo a boa consciência moralista ${ }^{19 "}$. Assim, "a hybris não nasce da falta mas do excesso de teoria, mais exatamente da inadequação entre a teoria e a prática ${ }^{20 "}$.

A partir desse breve e incompleto recorte, poderíamos, por ora, concluir que, quando um orador estrutura sua argumentação na phrónesis, está fundamentando seu discurso no logos. É preciso ponderar, entretanto, que, se a actio é a execução derradeira do discurso, é preciso separá-la da elocutio, que carrega a expressão, os modos de dizer, a construção de singularidades, o estilo de linguagem do autor e cujo propósito é a eficácia pela ação.

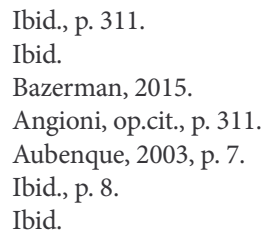


Nesse sentido, arriscaríamos dizer que na oralidade é possível separar teoricamente actio de elocutio, dadas as características inerentes à oratória, como proxêmica, gestualidade e eloquência, porém, na escrita, diríamos se tratar de algo difícil, senão quase impossível, de se verificar, uma vez que a distância entre os sujeitos do discurso, orador e auditório, é totalmente assimétrica, e a eficácia discursiva não pode ser verificada pari passu à sua proferição. Cabe ao orador, nesse caso, a capacidade comunicativa de delimitar seu auditório e o alcance de seu discurso.

Desse modo, alguns fatores que poderiam ser considerados na escrita são os elementos paratextuais previstos como recursos formais e linguísticos que cooperam para a eficácia do ato retórico, como a localização na página, a tipografia, a legibilidade, leiturabilidade, imagens, gráficos, diagramação etc. Enfim, se a phrónesis pode ser compreendida como uma "habilitação racional para agir ${ }^{21}$ ", é possível considerar que ela também "envolve o entendimento verdadeiro dos fins moralmente corretos, mas sua tarefa essencial não é justificar esses fins, mas sim delimitá-los pela avaliação correta dos fatores singulares ${ }^{22}$ ", pois, em última análise, a virtude é o valor máximo a ser alcançado pelo orador.

Enfim, quando pensamos na eficácia de um discurso, e nos meios para obtê-la, estamos diante do logos, que permite a atuação tanto na sintaxe como na semântica. A primeira, que atua na linguagem em seus aspectos formais (como dizer o que se quer dizer), e a segunda, em seus aspectos discursivos (como adequar o que se quer dizer com o como se quer dizer).

\section{O ethos institucional}

A construção do discurso ou ato retórico parte da ideia de que existem dois tipos de provas que ajudam "a enquadrar o modelo da argumentação $0^{23}$ ": as provas extrínsecas e as provas intrínsecas. Segundo Ferreira, as provas extrínsecas (ou extra-artísticas) "têm sua fonte numa circunstância externa", "são colhidas no mundo exterior e utilizadas em benefício dos propósitos do orador" e, enfim, "são eventuais e variáveis e dependem, sempre, de outras

\footnotetext{
21 Angioni, 2011, p. 315.

22 Ibid., p. 331.

23 Mateus, 2018, p. 104.
} 
esferas do conhecimento ${ }^{24 "}$. Desse modo, evidências concretas, como mancha de sangue, impressão digital, termos da lei, testemunhas, contratos, citação de autoridade, entre outros, podem ser utilizadas para compor um discurso retórico, desde que a serviço da persuasão por meio da argumentação. Mateus explica que "no gênero epidítico, utilizam-se provas extra-artísticas para enaltecer o indivíduo em causa referindo os seus feitos, os objetos simbólicos que alcançou (ex.: medalhas, troféus, diplomas etc.) ou a sua carreira política (ex.: o currículo dos cargos políticos ocupados) ${ }^{25}$ ".

Já as provas intrínsecas (ou artísticas) são "internas à retórica 26", são raciocínios que podem ser dedutivos (silogismos, entimemas), mas sem compromisso com a Lógica Formal, ou indutivos (exemplos). No sistema aristotélico, segundo Mateus,

as provas artísticas consistem no logos, pathos e ethos e definem uma argumentação orientada pelo raciocínio rigoroso (logos), dirigida às emoções humanas (pathos) e baseada no carácter e probidade humanos (ethos). (...) O orador possui assim a capacidade de confeccionar e trabalhar a dimensão racional, afetiva e íntegra dos seus discursos retóricos. A racionalidade, a afetividade e a probidade formam, deste modo, os registos ou timbres da argumentação ${ }^{27}$.

Da combinação dessas três provas podem ser elaborados discursos retóricos que circularão em diferentes contextos e para variados públicos, mas que visam sempre a mesma finalidade: a adesão do auditório. Para Mateus, "os discursos retóricos mais complexos combinam estas diferentes provas de forma minuciosa, com vista a oferecer ao auditório uma argumentação racionalmente convincente mas também emocionalmente interpeladora, capaz de despertar respeitabilidade ${ }^{28}$ ".

Nesse sentido, é possível constatar a existência desses elementos retóricos nas diversas manifestações humanas de linguagem e em diferentes esferas sociais de comunicação, concretizados no discurso, que, segundo Bakhtin ${ }^{29}$, apenas é possível existir efetivamente na forma de enunciados concretos de certos usuários da língua, concebidos como sujeitos do discurso. Tais enun-

\footnotetext{
24 Ferreira, 2010, p. 79.

25 Mateus, 2018, p. 104.

26 Ferreira, 2010, p. 80.

27 Mateus, op.cit., p. 105.

28 Ibid., p. 106.

29 Bakhtin, 2011.
} 
ciações concretas são os gêneros discursivos que Bakhtin divide em gêneros primários e secundários do discurso, em que os primários são produzidos de forma oral ou escrita, em realizações concretas de comunicação mais simples, conversacionais e cotidianas, como cartas familiares, diálogos argumentativos informais, mensagens em redes sociais, e-mails, textos prescritivos e instrucionais básicos, anedotas.

Já os gêneros secundários apresentam maior complexidade em sua composição, conteúdo temático e estilo de linguagem, como romances, peças teatrais, discursos científicos, discursos ideológicos, reportagens, artigos assinados, e surgem, segundo Bakhtin, "nas condições de um convívio cultural mais complexo e relativamente mais desenvolvido e organizado (predominantemente o escrito - artístico, científico, sociopolítico ${ }^{30 "}$. Em sua formação, os gêneros secundários “incorporam e reelaboram diversos gêneros primários (simples), que se formaram nas condições da comunicação discursiva imediata ${ }^{31 "}$.

Os gêneros primários transformam-se dentro dos secundários, perdem sua relação imediata com a realidade existente e com a realidade dos enunciados alheios, e servem de matéria-prima para produtores de discursos mais complexos que se valerão de phrónesis para manipular as diferentes estruturas, linguagem, nuances, timbres, que se efetivarão nas interações sociais.

A essa altura, é preciso esclarecer que compreendemos por ato retórico todo discurso que se utilize de argumentos para atingir um propósito. E que "todos os discursos são argumentativos, pois são uma reação responsiva a outro discurso ${ }^{32}$ ". Isso nos permite afirmar que a retórica opera na interação social num mundo de contingências, em que as coisas nem sempre são o que parecem e a verdade é relativa e multifacetada. Logo, a construção de atos retóricos pode ser observada cotidianamente nas diferentes esferas da comunicação humana e por meio de variados gêneros discursivos, com maior ou menor grau de persuasão, por meio de argumentos nem sempre explícitos, mas sempre com argumentatividade.

De qualquer modo, mesmo havendo a combinação das três provas para o discurso retórico, o ethos é considerado, tradicionalmente, "a mais eficaz das provas porque contra a honradez, integridade e nobreza do caráter pouco se pode argumentar ${ }^{33}$ ". O ethos é definido como a imagem de si, "instância

\footnotetext{
$30 \quad$ Ibid., p. 263.

31 Ibid.

32 Fiorin, 2014, p. 69.

33 Mateus, 2018, p. 111.
} 
subjetiva do próprio enunciador ${ }^{34}$ ", construída no e a partir do discurso e que "opera no registro da credibilidade e por isso o orador deve mostrar-se sincero, franco e verdadeiro ${ }^{35}$ ".

Mais modernamente, o ethos, segundo Ferreira, "é a imagem que o orador

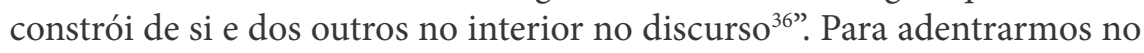
campo do ethos moderno, consideramos ainda o entendimento de Meyer, para quem o ethos é "um domínio, um nível, uma estrutura", que não se limita ao sujeito empírico, ao orador diante de um auditório nem ao autor criador que age por meio da linguagem literária ou não literária, mas o ethos que "se apresenta de maneira geral como aquele ou aquela com quem o auditório se identifica ${ }^{37}$." Conforme Ferreira, há diferentes abordagens que admitem o ethos institucional a partir de uma perspectiva linguística (Ducrot) e outra sociológica (Bordieu), "formado pela articulação de um ethos puramente discursivo e de outro, exterior ao discurso ${ }^{38 "}$.

A despeito das diferentes posições contemporâneas, Ferreira afirma que, em uma análise retórica é possível "encontrar um orador que constrói, sobretudo, o ethos de outras personagens ou de classes sociais e de instituições. Nesse caso, pode-se ressaltar a função do orador efetivo (é jornalista, é político, é publicitário) e, depois, analisar o ethos 'alheio' que se instaura no interior do discurso ${ }^{39}$ ". Assim, para a elaboração de um "discurso autorizado", ou seja, que reflete as posições de uma autoridade, aceitamos o fato de que "qualquer discurso revela marcas das instituições de onde derivam e os representantes da instituição, que possuem discurso autorizado, criam seus discursos a partir dessa base institucional que os torna 'competentes ${ }^{30}$ ". A mesma posição é compartilhada por Guimarães ao afirmar que

não se pode divorciar a figura do falante dos liames institucionais aos quais ele está ligado. Não se distancia o sujeito do discurso do seu campo de atuação profissional. Assim, não se pode conceber o espírito dos discursos didático e político, por exemplo, fora das propostas das instituições por eles representados ${ }^{41}$.

\footnotetext{
34 Ferreira, 2010, p. 90.

35 Mateus, 2018, loc.cit.

36 Ferreira, 2010, loc.cit.

37 Meyer, 2007, p. 35.

38 Ferreira, op.cit., p. 90.

39 Ibid., p. 92.

40 Ibid., p. 95.

41 Guimarães, 2008, p. 2.
} 
O problema do discurso institucional é sua natureza autoritária e prescritiva, pois precisa fixar leis, regras, normas, convenções, geralmente acompanhadas de valores e crenças nem sempre aceitos por todos os segmentos sociais. $\mathrm{O}$ orador, privilegiado pelas condições próprias desse tipo de discurso, tem a seu favor não só a credibilidade, mas a força da autoridade da instituição que ele representa. Entretanto, diante da exacerbação do discurso autorizado quando se torna autoritário, não há espaço para a retórica, apenas para a violência verbal ou física.

Se o ethos institucional produz um discurso autorizado ou mesmo autoritário, que, segundo Ferreira, "alimenta e configura o chamado discurso dominante", por outro lado, há o discurso instituinte, que resulta da negação do auditório em partilhar da crença ou valores dominantes, por meio de um "processo de desconstrução do que é dominante ${ }^{42}$ ". Disso podemos depreender que um jornalista ou um publicitário, por exemplo, podem assumir papeis conflitantes com as instituições que representam, pois constroem discursos limítrofes daquilo que é dominante ou instituinte. A começar pela forma textual, que passa por "manuais de redação e estilo", até pela forma discursiva, que deve atender a uma pauta preestabelecida pelo editor-chefe. Nesse sentido, talvez o ombudsman seja o único orador admitido pela instituição para questionar suas próprias posições.

Finalmente, "a posição do ethos institucional do orador marca sua vinculação com o saber, com uma dada filosofia - simulação que se ajusta também à maneira como o orador passa a se comunicar com seu auditório ${ }^{43}$ ", por isso, o saber prático de um profissional de comunicação, por exemplo, está ligado à sua experiência de produtor de discursos. Para tanto, na condição de autor de um discurso autorizado, ele precisará focar o discurso no próprio discurso, portanto no logos.

\section{Discursos à luz do saber prático}

O advento das tecnologias digitais de informação e de comunicação (TDIC) ampliou sobremaneira as possibilidades comunicativas, encurtou a distâncias entre as pessoas e abriu uma infinidade de modos de aquisição de

$42 \quad$ Ferreira, op.cit., p. 98.

43 Guimarães, op.cit., p. 2. 
serviços e produtos. $\mathrm{O}$ acesso a essa tecnologia, ainda que não seja possível para milhões de desempregados, desalentados e miseráveis, de alguma forma interfere na vida de todos os brasileiros. Em alguns minutos, por exemplo, uma pessoa pode arrecadar na internet dinheiro para uma causa humanitária em poucas horas e vindo de todas as partes do Brasil e do mundo. Pessoas criam aplicativos para alertar sobre pontos da cidade com maior risco de assaltos. Boas ações para bons propósitos. Infelizmente, a bondade e a honestidade, duas virtudes tão caras a um cidadão de bem, nem sempre são colocadas em primeiro plano.

Sob outro aspecto, a internet e as redes sociais propiciam espaços para trocas de mensagens e debates sobre as mais variadas questões. Nesses novos cenários, a lógica formal perde a vez e abre-se espaço para a retórica ou para a erística ${ }^{44}$, em que os sujeitos debatem ideias ou se digladiam em defesa de seus pontos de vista. Na primeira, pela persuasão com argumentos válidos; na segunda, pela agressão com ofensas ou incitação à violência.

Apesar dessa possibilidade, para nossa análise e no plano do conteúdo oficial com viés informativo, selecionamos dois textos com conteúdos antagônicos. O primeiro é intitulado "MEC lança programa para aumentar a autonomia financeira de universidades e institutos", artigo publicado no Portal MEC, em 17 de julho de 2019, assinado por Guilherme Pera e Dyelle Menezes, com a finalidade de apresentar o programa "Future-se", que propõe mudanças na gestão das universidades e institutos federais. $\mathrm{O}$ segundo texto é intitulado "Docentes de todo o país se mobilizam contra o Future-se e em defesa da Educação Pública e Gratuita", artigo publicado no site oficial do Sindicato Nacional dos Docentes das Instituições de Ensino Superior (ANDES), em 24 de julho de 2019, sem autoria explícita, com a finalidade de informar sobre a mobilização contra o programa "Future-se", apresentado pelo MEC.

Embora o texto do MEC seja assinado por dois autores, o conteúdo aparentemente informativo traz diversos posicionamentos oficiais que justificam o programa ora anunciado. Assim, o ethos institucional, apesar da fala autorizada do orador, é construído a partir de termos que buscam amenizar o impacto das "novas" propostas do governo. $\mathrm{O}$ texto possui 5.470 caracteres (cerca de três laudas) e, logo no primeiro parágrafo, afirma:

44 Erística é, etimologicamente, "a disputa argumentativa, a contenda, a altercação de motivos e uma logomaquia, ou debate de razões, exacerbada” (MATEUS, 2011, p. 52). 
Inédito e inovador, o programa propõe uma mudança de cultura nas instituições públicas de ensino superior: maior autonomia financeira a universidades e institutos federais ${ }^{45}$. (grifos nossos)

Os qualificadores "inédito" e "inovador" dão o tom da proposta oficial e justificam o discurso subsequente. Há um cuidado, outra acepção para phrónesis ${ }^{46}$, em apresentar um programa confiável em que só pelo fato de ser "inédito" ou "inovador" já seria bom e justo, recursos retóricos que buscam a confiabilidade do auditório. O termo "mudança na cultura" pressupõe uma necessidade que contrapõe algo velho ou ultrapassado. Obviamente que se tratam de valores existentes em um contexto da administração da educação pública, cujas decisões importantes são tomadas por um colegiado formado por gestores, professores e comunidade universitária.

Nesse sentido, o ethos institucional que representa o discurso do MEC parece se distanciar das posições públicas assumidas pelo ministro da Educação que, em diversos momentos por meio do Twitter e de entrevistas, havia acusado universidades federais de serem espaços ocupados por "reitores (ditos) de esquerda" ${ }^{47}$, e professores e estudantes como promotores de "balbúrdia"48 devido a manifestações contrárias a políticas de sua pasta.

Obviamente, o texto informativo opera nos limites da impessoalidade e o autor, valendo-se do saber prático ou prudência, constrói o discurso de modo objetivo. Assim, o termo "maior autonomia financeira" vem contrapor a ideia de que o governo corta gastos por mero capricho ou perseguição a universidades dispostas ao enfrentamento. Nesse sentido, "mais autonomia" conota uma promessa e incute um desejo, tendo prohairesis como "ponto de partida" e "princípio motivador que leva a agir" ${ }^{49 "}$ e phrónesis como elemento de prudência na construção do discurso.

No segundo parágrafo, o orador revela seu alinhamento com o discurso oficial que extrapola a Educação:

45 Brasil. MEC, 17 jul. 2019.

46 Cf. DIDEROT, 1751.

47 Cf. "Ministro da Educação ironiza reitores 'de esquerda' de universidades”, notícia publicada na revista Veja, em $1^{\circ}$ de maio de 2019. Disponível em https://veja.abril.com.br/educacao/ministro-da-educacao -ironiza-reitores-de-esquerda-de-universidades/. Acessado em 12ago.2019.

48 Cf. "MEC cortará verba de universidade por 'balbúrdia' e já enquadra UnB, UFF e UFBA”, notícia publicada no portal Estadão, em 30 de abril de 2019. Disponível em https://educacao.estadao.com.br/ noticias/geral,mec-cortara-verba-de-universidade-por-balburdia-e-ja-mira-unb-uff-e-ufba,70002809579. Acessado em 12ago2019.

49 Angioni, 2011, p. 306. 
Assim como ocorre na reforma da Previdência, sustentabilidade financeira e responsabilidade com o futuro são pilares do projeto. $\mathrm{O}$ fomento à captação de recursos próprios e ao empreendedorismo são algumas das propostas ${ }^{50}$. (grifos nossos)

O discurso retórico, com foco no logos, utiliza argumento por comparação para justificar os conceitos de "sustentabilidade financeira" e "responsabilidade com o futuro" da reforma da Previdência, política também questionada pela comunidade universitária. Ora, uma afirmação pressupõe também uma negação, assim, de forma sutil e prudente, pode-se inferir que as universidades seriam "insustentáveis" financeiramente e se não aderirem às mudanças anunciadas estariam sendo "irresponsáveis", pois não se preocupam com o futuro. Essa sutileza do dizer pertence ao domínio da phrónesis, perceptível no jogo de palavras na superfície do texto (logos) e na semântica verificada em camadas mais profundas, pelos sentidos da expressão (elocutio). Assim, temos a ideia de solidez e equilíbrio acentuada pelo termo "pilares", e de incentivo, suporte e iniciativa, respectivamente, por termos como "fomento", "recursos próprios" e "empreendedorismo".

Nos parágrafos seguintes, o discurso identifica o seu oponente, revestese de princípios democráticos e participativos e, novamente, contrapõe o discurso do oponente:

(...) o programa retira algumas barreiras burocráticas que as universidades enfrentam.

O processo respeitará o princípio da publicidade. A proposta do MEC vai passar por consulta pública até o dia 15 de agosto. A população poderá colaborar com o programa. As contribuições serão compiladas e uma proposta de mudança na legislação, apresentada posteriormente.

A adesão ao Future-se será voluntária. As universidades e os institutos federais não serão privatizados. O governo continuará a ter um orçamento anual destinado para as instituições ${ }^{51}$. (grifos nossos)

50 Brasil. MEC, 17 jul. 2019.

51 Brasil. MEC, 17 jul. 2019. 
Sempre apresentando sutilezas, o orador escolhe cuidadosamente as palavras, com metáforas e eufemismos, como "barreiras burocráticas" para referir-se àquilo que causaria o suposto mau funcionamento das universidades federais. Dessa forma, o ethos institucional, mesmo tendo a prerrogativa de autoridade, revela uma imagem de si democrática e que respeita a opinião pública (diferentemente das declarações de membros do governo e do próprio presidente da República, repercutidas largamente na grande mídia). Isso é verificado pela escolha de expressões como "publicidade", "consulta pública", "colaborar", "contribuições" e "proposta" e que permite ao orador construir uma imagem positiva do governo. E, como resposta a possíveis críticas, o orador procura afastar a ideia de privatização e informa que a adesão ao programa "Future-se" é voluntária.

De forma sintética, o texto apresenta três eixos complementares ao programa: "Gestão, Governança e Empreendedorismo", "Pesquisa e Inovação" e "Internacionalização". Para nossa análise, debruçar-nos-emos sobre o primeiro eixo. Pois bem, como lista de ações pretendidas, o texto utiliza verbos na forma infinitiva e apresenta informações que dão margem a diferentes interpretações, mas que não deixam de revelar a ideologia liberal que pauta $\mathrm{o}$ atual governo, embora este afirme governar sem ideologia.

- Promover a sustentabilidade financeira, ao estabelecer limite de gasto com pessoal nas universidades e institutos - hoje, em média,

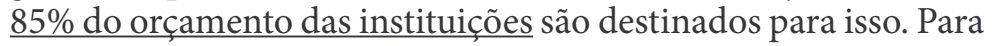
a administração pública, a Lei de Responsabilidade Fiscal (LRF) estabelece percentual máximo de $60 \%$;

- estabelecer requisitos de transparência, auditoria externa e compliance;

- criar ranking das instituições com prêmio para as mais eficientes nos gastos;

- gestão imobiliária: estimular o uso de imóveis da União e arrecadar por meio de contratos de cessão de uso, concessão, fundo de investimento e parcerias público-privadas (PPPs);

- propiciar os meios para que os departamentos de universidades/ institutos arrecadem recursos próprios, com estímulo à competição entre as unidades; 
- autorizar naming rights (ter o nome de empresas/patrocinadores e patronos) nos campi e em edifícios, o que possibilitaria a modernização e manutenção dos equipamentos com ajuda do setor privado. (grifos nossos)

Vemos que o discurso autorizado, que constrói o ethos institucional do MEC em busca de adesão de seu auditório, apresenta de forma sucinta algumas práticas típicas da administração de empresas do setor privado: "compliance" (conjunto de disciplinas a fim de cumprir normas e regulamentos), "ranking" e premiação (meritocracia), "contratos de cessão de uso", "concessão", "competição", "naming rights". O tom do discurso é de certa forma didático, explicativo, denotando naturalidade que condiz com a ideia inicial de ser "inédito" e "inovador".

Já o discurso da ANDES, embora expresse um ethos da entidade sindical, apresenta um discurso instituinte, no sentido de levar o auditório não só a negar a crença no discurso dominante, mas também a desconstruí-lo ${ }^{52}$. Por isso, em seus 6.680 caracteres, prevalecem no texto termos relacionados à mobilização do auditório. Assim, a deliberação é uma premissa que surge como consenso supostamente partilhado entre orador e interlocutores.

Nos dois primeiros parágrafos, o orador classifica o programa "Future-se" como projeto de "privatização da Educação Pública e Gratuita" e conclama o leitor a "aprofundar o debate sobre o desmonte da Educação Pública Federal" que precisa ser barrado. Nesse sentido, existe um forte apelo ao pathos pela ação, elencando doze instituições de ensino superior que já programaram atos contrários ao programa do MEC. Somente após informar sobre a organização dos atos, o texto traz contra-argumentos ao "Future-se", cedendo a fala a um dos membros do sindicato:

O Future-se para nós representa um ataque à autonomia universitária e uma proposta clara de desmonte e privatização das universidades, não só no contexto da questão de contratação de docentes e técnicos-administrativos, mas também uma forma, inclusive, das instituições federais serem subordinadas a empresas e a entidade, que querem lucrar com a produção do conhecimento na universidade pública. Isso fica bem evidenciado nesse programa $(\ldots)^{53}$. (grifos nossos)

52 Ferreira, 2010.

53 ANDES, 24 jul. 2019. 
O discurso autorizado assume um tom de denúncia e necessidade de ação contra "um ataque à autonomia universitária". Note que o termo "autonomia" possui aqui um sentido mais amplo do que o utilizado pelo MEC ("autonomia financeira"), pois, para a entidade de classe, a autonomia deve ser mantida em todos os aspectos no interior da administração pública. Em seguida, considera a proposta como "um desmonte e privatização das universidades", ações jamais assumidas pelo discurso oficial.

Para além de uma questão semântica acerca do termo "privatização", pois existem formas diretas e indiretas de o setor privado participar da gestão pública, o discurso do sindicato justifica sua crítica a partir dos "cortes" de verba para as instituições de ensino superior, ao passo que o governo afirma se tratar de "contingenciamento" de verbas discricionárias. O argumento é construído como causa e consequência em que o corte de verbas deverá "forçar" os gestores a aderirem ao "Future-se", não de forma voluntária, mas pela "situação de penúria", consequência do corte ou contingenciamento.

Nesse contexto, o sindicato, legitimado pelos trabalhadores para representá-los, goza de um saber prático e de prudência no sentido de conhecer e vivenciar os meandros da luta por direitos conquistados. Nota-se, pois, que o discurso institucional da ANDES estrutura-se na phrónesis e fundamenta-se no logos, primeiro porque busca uma "habilitação racional para agir"; segundo, porque "envolve o entendimento verdadeiro dos fins moralmente corretos" ${ }^{\prime 54}$; terceiro, porque a phrónesis é contingente, logo, a tarefa essencial é delimitar os fins pela análise correta dos fatores peculiares que cercam o tema.

Enfim, no mundo da doxa e na contingência "calculativa" e "opinativa" da phrónesis, os discursos do MEC e da ANDES representam discursos autorizados, com ethos institucional e ethos instituinte, respectivamente, fundamentados no logos. Por isso, a sintaxe e a semântica são privilegiadas como parte do sistema retórico que se demonstra na elocutio, pela força e propriedade da expressão linguística e discursiva.

\section{Considerações finais}

A argumentação estruturada na phrónesis fundamenta seu discurso no logos. Além disso, atua na elocutio como construção expressiva do estilo, do

54 Angioni, 2011, p. 311. 
timbre, do como dizer o que se quer dizer. $\mathrm{O}$ ethos institucional - e instituinte -, por sua vez, aposta no próprio discurso e na posição privilegiada de fala autorizada. Ainda que se dirija ao mesmo auditório particular, o discurso é construído com criteriosa escolha lexical e razões ligadas ao contexto retórico dentro do mundo da doxa.

A phrónesis, como vimos, é contingente, por isso comporta diferentes pontos de vista e as verdades daí decorrentes. Os discursos autorizados, dessa forma, utilizam com maior frequência a phrónesis que expressa a prudência, a sensatez, a credibilidade, a racionalidade, a razoabilidade, a competência, a ponderação e o discernimento, qualidades mais presentes no logos.

Por fim, o velho artesão e seu banco, o jovem publicitário e sua peça propagandística e os autores de discursos institucionais utilizam-se de sabedoria prática, de prudência e cuidado, o que lhes exige a mobilização de diferentes formas de saberes: conhecimento prévio ou enciclopédico, experiência de vida e domínio técnico-discursivo em seu campo de atuação profissional, que certamente o auxiliarão nas melhores escolhas para atingir seus objetivos. 


\section{Referências}

ANDES (SINDICATO NACIONAL DOS DOCENTES DAS INSTITUIÇÕES DE ENSINO SUPERIOR). Docentes de todo o país se mobilizam contra o Futurese e em defesa da Educação Pública e Gratuita. Publicado em 24 de jul. de 2019. Disponível em https://www.andes.org.br/conteudos/noticia/docentes-de-todo-o-paisse-mobilizam-contra-o-future-se-e-em-defesa-da-educacao-publica-e-gratuita1. Acesso em 10 ago.2019.

ANGIONI, L. Phronesis e virtude do caráter em Aristóteles: comentários a Ética a Nicômaco VI. Dissertatio, UFPel [34, 2011] 303 - 345. Disponível em https:// periodicos.ufpel.edu.br/ojs2/index.php/dissertatio/article/view/8706/5749. Acesso em 19 fev. 2019.

ARISTÓTELES [384-322 a.C.]. Retórica. São Paulo: Folha de S.Paulo, 2015. Trad. Manuel Alexandre Júnior, Paulo Farmhouse e Abel do Nascimento Pena.

Trad. Eudoro de Souza. Ética a Nicômaco. 4. ed. São Paulo: Nova Cultural, 1991.

. De caelo. Edição D. J. Allan. Oxford: Oxford University Press, 1936. (Oxford Classical Texts).

AUBEnQue, P. [1963]. A prudência em Aristóteles. São Paulo: Discurso Editorial, 2003. Trad. Marisa Lopes.

BAKHTIN, M. Estética da criação verbal. São Paulo: WMF Martins Fontes, 2011. Trad. do russo Paulo Bezerra.

BAZERMAN, C. Retórica da ação letrada. São Paulo: Parábola editorial, 2015.

BRASIL. MEC. MEC lança programa para aumentar a autonomia financeira de universidades e institutos. Escrito por Guilherme Pera e Dyelle Menezes e publicado em 17 de jul. de 2019. Disponível em http://portal.mec.gov.br/ ultimas-noticias/212-educacao-superior-1690610854/78211-mec-lanca-programa-para -aumentar-a-autonomia-financeira-de-universidades-e-institutos. Acesso em 10 ago.2019.

DIDEROT, D. L'Encyclopédie, 1re éd. 1751 (Tome 13, p. 527-528) - Tradução livre. Disponível em https://fr.wikisource.org/wiki/L\%E2\%80\%99Encyclop\%C3\%A9die/1re_\%C3\%A9dition/PRUDENCE. Acesso em 12 ago.2019.

FERREIRA, L. A. Leitura e persuasão: princípios de análise retórica. São Paulo: Contexto, 2010.

FIORIN, J. L. Argumentação e discurso. Bakhtiniana, São Paulo, n. 9 (1), p. 53-70, Jan./Jul. 2014.

GAUTHIER, R. La morale d'Aristote. Paris: PUF, 1958.

GUIMARÃES, E. O ethos na argumentação. SIMELP - I Simpósio Mundial de Estudos da Língua Portuguesa (São Paulo), 2008.

MATEUS, S. Introdução à Retórica no século XXI. Covilhã (Portugal): Labcom.IFP/Universidade da Beira Interior, 2018.

MEYER, M. A retórica. São Paulo: Ática, 2007. 